\title{
Commentary \\ Recent translational research: circulating tumor cells in breast cancer patients
}

\author{
Volkmar Müller ${ }^{1}$, Daniel F Hayes ${ }^{2}$ and Klaus Pantel ${ }^{3}$
}

\author{
${ }^{1}$ Department of Gynecology, University Medical Center Hamburg-Eppendorf, Martinistrasse 52, 20246 Hamburg, Germany \\ ${ }^{2}$ Breast Oncology Program, University of Michigan Comprehensive Cancer Center, 6312 Cancer Center, 1500 E. Medical Center Drive, Ann Arbor, Ml \\ 48109-0942, USA \\ ${ }^{3}$ Institute of Tumor Biology, University Medical Center Hamburg-Eppendorf, Martinistrasse 52, 20246 Hamburg, Germany
}

Corresponding author: Klaus Pantel, pantel@uke.uni-hamburg.de

Published: 31 August 2006

This article is online at http://breast-cancer-research.com/content/8/5/110

(c) 2006 BioMed Central Ltd

\begin{abstract}
In breast cancer patients, hematogenous tumor cell dissemination can be detected, even at the single cell level, by applying immunocytochemical and molecular assays. Various methods for the detection of circulating tumor cells in the peripheral blood have been described. Results from recently reported studies suggest that circulating tumor cell levels may serve as a prognostic marker and for the early assessment of therapeutic response in patients with metastatic breast cancer. However, in early-stage breast cancer, the impact of circulating tumor cells is less well established than the presence of disseminated tumor cells in bone marrow; several clinical studies have demonstrated that cells of the latter type are an independent prognostic factor at primary diagnosis. In this article we briefly summarize recent studies examining the presence of circulating tumor cells in the blood and discuss further clinical applications.
\end{abstract}

\section{Introduction}

Adjuvant systemic therapy has contributed substantially to the decline in mortality from breast cancer in the Western world [1]. However, adjuvant systemic therapy is associated with substantial cost and toxicity. With the use of traditional prognostic factors, it is still not possible to reliably identify those breast cancer patients who will relapse with metastatic disease [2]. Research efforts have therefore been undertaken to identify additional parameters enabling individual risk assessment. In addition to their role as prognostic factors, these parameters may also serve as targets for new therapeutic approaches (for example HER-2/neu and trastuzumab) [3].

Classically, prognostic factor research has been focused on molecular characteristics of the primary tumor. However, it seems more logical to examine micrometastases in distant sites as an indication of future cancer behavior. In that regard, immunocytochemical and molecular assays enable the specific detection of systemically detected metastatic tumor cells, even at the single-cell stage, in the blood and bone marrow (BM). These technical advances provide an opportunity to study one of the first crucial steps in the metastatic cascade.

Because BM collection is invasive and inconvenient, many investigators have studied techniques to detect and characterize tumor cells in blood. Recently reported studies indicate that, with modern detection techniques, circulating tumor cells (CTCs) could provide a reliable and convenient source for clinically relevant analysis. Pretreatment CTC levels seem to be prognostic in women with metastatic disease starting a new therapy. Moreover, CTC levels may also be important in determining therapeutic efficacy. Fewer data are available for CTCs in patients with early stage disease.

In this review we consider the current aspects in the field of CTC detection in breast cancer patients and discuss perspectives for clinical and research applications.

\section{Techniques for detecting CTCs: new developments for tumor cell enrichment and cell detection}

Enumeration of CTCs in human blood is fraught with many challenges. First, one must separate these rare cancer cells from billions of erythrocytes and millions of leucocytes present in $10 \mathrm{ml}$ of blood, and then one must confirm that the identified 'event' is, indeed, a CTC. Many strategies have been used to separate CTCs from normal blood cells (e.g. centrifugal migration through Ficoll gradient or filtration), and 
to confirm the malignant origin of the cells on the basis of the identification of epithelial or breast-specific markers.

For rigorous multicenter studies and/or routine clinical use, it is of importance to demonstrate reproducibility of evaluations and stability of blood samples, to allow shipment of samples. With modern assay systems, such requirements can be fulfilled [4]. In this regard, recent developments of new enrichment systems for CTCs seem to provide an accurate and reliable method to identify and characterize these rare events $[5,6]$. For example, the nearly entirely automated system, designated CellSearch ${ }^{\mathrm{TM}}$, has been cleared by the US Federal Drug Administration. This system combines immunomagnetic enrichment and fluorescent immunocytochemical characterization of these rare events. In a prospective, multi-institutional clinical trial, CTC detection with this system provided significant prognostic information both before and soon ( 4 weeks) after initiation of chemotherapy in patients with measurable metastatic breast cancer $[6,7]$. A prospective randomized clinical trial is planned by the US Breast Cancer Intergroup, led by the Southwest Oncology Group, to evaluate whether patients with metastatic breast cancer who have persistently elevated CTC levels after one cycle of first-line chemotherapy benefit from an early change of therapy.

\section{PCR-based assays for CTC detection}

Expression of epithelial and/or breast cancer-specific genes can be exploited to provide evidence of disseminated tumor cells (DTCs). In addition to immunologic techniques, PCR techniques have been employed to detect these rare events. The major limiting factor for the detection of single tumor cells by RT-PCR is illegitimate low-level transcription of tumor-associated or epithelium-specific genes in normal cells [8]. Quantitative RT-PCR may increase discrimination between mRNA expression in normal cells and tumor cells, thereby increasing the specificity of the RT-PCR approach. In one study, Ring and colleagues [9] compared immunomagnetic separation or cell filtration combined with laser scanning cytometry with a multimarker real-time RT-PCR assay for the detection of breast cancer cells. The multimarker real-time RT-PCR assay was found to be the most sensitive technique for the detection of CTCs [9]. However, it is not clear which of the methods provides clinical relevant information.

Two separate studies have suggested that RT-PCR detection of CTCs is associated with poor prognosis. One of these employed cytokeratin 19 RT-PCR in the blood of nonmetastatic breast cancer patients before adjuvant therapy [10], whereas in the other a multimarker PCR assay was used to detect CTCs in metastatic patients [11]. CTC detection by PCR for cytokeratin 19 before neoadjuvant chemotherapy has also been reported to be associated with an increased risk for recurrence [12]. These intriguing but preliminary results require validation in prospective multicenter studies, because assay conditions vary between studies and there is no consensus regarding these conditions.

\section{Can blood examination replace BM aspiration?}

Results from individual studies, and a recently published pooled analysis of several studies, have consistently demonstrated that the presence of DTCs in BM has a strong prognostic impact on patient survival [13]. Because BM aspiration and biopsy are invasive and inconvenient, several investigations have addressed whether one might garner the same information from CTCs. Preliminary studies suggest that CellSearch ${ }^{\mathrm{TM}}$ can be used to detect DTCs in BM and CTCs in blood of patients with primary breast cancer [14,15]. Optimal cutoff values for different patient groups are still under investigation. At the San Antonio Breast Cancer Symposium in 2005, it was reported that prognostic information from CTC determination can also be obtained in patients treated with endocrine therapy but that the optimal time point for the evaluation of CTCs in these patients might be later during the course of treatment than for patients treated with chemotherapy [16]. In addition, for certain patient groups (for example, patients with estrogen receptornegative tumors or patients treated with chemotherapy) the clinically relevant number of CTCs might be lower than the five cells previously described [16].

Recent studies suggest that the frequency of CTCs in blood seems to be lower than that of DTCs in BM. Conventional Ficoll gradient centrifugation might therefore not provide sufficient enrichment of malignant cells. This could explain the lack of clinical relevance of CTC detection described in earlier studies.

Other methods of detection of CTCs and DTCs have also been compared $[5,17,18]$. Using immunocytochemistry, Piegra and colleagues [18] showed a correlation between the detection of CTCs in the blood and DTCs in BM of patients with primary breast cancer at the time of surgery. However, although they did detect an association between the two, only the presence of DTCs in BM provided significant prognostic information. In a study by Wiedswang and colleagues [17], CTCs and DTCs from BM were examined by immunocytochemistry from breast cancer patients with a median time of 40 months after operation. Both the presence of CTCs and that of DTCs in BM was significantly associated with disease-free survival and breast cancer-specific survival, and the presence of both CTCs and DTCs resulted in an especially poor prognosis. However, this study did not exclude patients who had relapsed before the sampling of blood or BM. Excluding the patients with breast cancer-related events before the sample collections, CTC detection was not significantly associated with disease-free survival/distant-disease-free survival, in contrast to DTC detection [17]. Kataoka and colleagues [19] examined blood and $\mathrm{BM}$ at the time of surgery for the presence of tumor cells with a quantitative RT-PCR assay for cytokeratin 7 mRNA. 
The presence of CTCs in blood, but not DTCs in BM, was correlated with an shorter distant metastasis-free survival. In multivariate analysis, the presence of CTCs was an independent prognostic factor in lymph-node-negative patients [19]. This is in contrast to a study of Benoy and colleagues [20], who found a prognostic impact only for BM but not for blood with the use of RT-PCT for cytokeratin 19 and mammaglobin. This study also included patients with metastatic breast cancer.

Currently, these findings do not support a change from DTC detection from BM to CTC analysis. However, they do suggest that the presence of CTCs could provide information additional to that gained from DTC analysis.

\section{Molecular characterization of CTCs}

Recent technical developments permit an examination of the genome of even single DTCs. Using immunocytochemistry, immunofluorescence, and/or fluorescence in situ hybridization (FISH), several groups have reported tumor-antigen expression and/or chromosomal aberrations of DTCs in BM and CTCs, indicating the malignant origin of these disseminated cells and indicating genetic heterogeneity $[2,21]$.

The biologic properties of CTCs are not yet well understood. It seems that these cells have little proliferative potential [5]. With current techniques, it is also possible to perform gene expression profiling from CTCs $[22,23]$. This enables studies that should allow deeper insights into the mechanisms allowing CTCs to form manifest metastasis. For example, it seems that, for breast cancer, only a small proportion of tumor cells, so-called 'cancer stem cells', have the capacity for self-renewal and unlimited growth [24]. In view of the resistance of DTCs and CTCs to chemotherapy it is possible that some of these cells have stem-cell properties. Identifying these 'metastatic stem cells' will be the one of the challenges for future research.

One aspect of clinical importance is the identification of therapeutic targets such as HER-2/neu on CTCs. HER-2 can be detected on CTCs with cytogenetic [21], immunocytochemical $[25,26]$ and PCR methods [27]. There are several possible implications of these findings. For example, it has been reported that nearly one-third of patients whose primary tumors were reportedly negative for HER-2 had CTCs with amplified HER-2 (as determined by FISH). Given the extraordinary impact of trastuzumab (Herceptin), a humanized monoclonal antibody directed against HER-2, in both the metastatic and adjuvant settings, monitoring CTCs for HER-2 could have an enormous influence on the application of this therapy. In addition, the presence of HER-2-positive CTCs seems to be associated with an impaired prognosis $[26,27]$.

\section{Conclusions and perspectives}

Besides the prognostic information gained from CTCs, they may also provide a tool for predicting or monitoring the efficacy of systemic therapy. The study with the highest level of evidence performed so far has been in patients with metastatic disease. However, CTC measurements might also have particular clinical relevance in the context of adjuvant systemic therapy. Indeed, adjuvant therapeutic efficacy can currently be assessed only in large-scale clinical trials after observation periods of several years. An assay that permits the assessment of treatment effects in this context is of high clinical importance. It was previously shown that CTCs can be detected during and after adjuvant or neoadjuvant chemotherapy $[5,28]$, but the clinical impact of this finding is still unclear.

Prospective clinical studies are now ongoing to evaluate whether the eradication of CTCs in the blood (and also DTCs in $\mathrm{BM}$ ) is correlated with a longer disease-free period and overall survival in the adjuvant setting and whether therapy guided by CTC testing is able to improve the outcome for metastatic patients. An additional important goal is the possibility of identifying metastatic-tumor-specific targets so as to improve therapy regimens.

\section{Competing interests}

VM declares no competing interests. DH received research funding from Immunicon and occasional honoraria for speaking engagements from Veridex. KP is co-founder of Micromet AG, Munich, Germany.

\section{References}

1. Berry DA, Cronin KA, Plevritis SK, Fryback DG, Clarke L, Zelen M, Mandelblatt JS, Yakovlev AY, Habbema JD, Feuer EJ: Effect of screening and adjuvant therapy on mortality from breast cancer. N Engl J Med 2005, 353:1784-1792.

2. Pantel K, Brakenhoff $\mathrm{RH}$ : Dissecting the metastatic cascade. Nat Rev Cancer 2004, 4:448-456.

3. Johnson ML, Seidman AD: Emerging targeted therapies for breast cancer. Oncology (Huntingt) 2005, 19:611-618.

4. Riethdorf S, Müller V, Coith $C$, Baack K, Jänicke F, Fritsche $H$, Jackson S, Gornet T, Pantel K: Detection of circulating tumor cells in peripheral blood of patients with metastatic breast cancer - a multi-center validation study of the CellSearch ${ }^{\mathrm{TM}}$ system [abstract]. Proc Am Assoc Cancer Res 2006, 47:5146.

5. Müller V, Stahmann N, Riethdorf S, Rau T, Zabel T, Goetz A, Jänicke $F$, Pantel K: Circulating tumor cells in breast cancer: correlation to bone marrow micrometastases, heterogeneous response to systemic therapy and low proliferative activity. Clin Cancer Res 2005, 11:3678-3685.

6. Cristofanilli M, Budd GT, Ellis MJ, Stopeck A, Matera J, Miller MC, Reuben JM, Doyle GV, Allard WJ, Terstappen LW, et al.: Circulating tumor cells, disease progression, and survival in metastatic breast cancer. N Engl J Med 2004, 351:781-791.

7. Cristofanilli M, Hayes DF, Budd GT, Ellis MJ, Stopeck A, Reuben JM, Doyle GV, Matera J, Allard WJ, Miller MC, et al.: Circulating tumor cells: a novel prognostic factor for newly diagnosed metastatic breast cancer. J Clin Oncol 2005, 23:1420-1430.

8. Zippelius A, Kufer P, Honold G, Kollermann MW, Oberneder R, Schlimok G, Riethmuller G, Pantel K: Limitations of reversetranscriptase polymerase chain reaction analyses for detection of micrometastatic epithelial cancer cells in bone marrow. $J$ Clin Oncol 1997, 15:2701-2708.

9. Ring AE, Zabaglo L, Ormerod MG, Smith IE, Dowsett M: Detection of circulating epithelial cells in the blood of patients with breast cancer: comparison of three techniques. $\mathrm{Br} J \mathrm{Cancer}$ 2005, 92:906-912.

10. Stathopoulou A, Vlachonikolis I, Mavroudis D, Perraki M, Kouroussis C, Apostolaki S, Malamos N, Kakolyris S, Kotsakis A, Xenidis 
$\mathrm{N}$, et al:: Molecular detection of cytokeratin-19-positive cells in the peripheral blood of patients with operable breast cancer: evaluation of their prognostic significance. J Clin Oncol 2002, 20:3404-3412.

11. Weigelt B, Bosma AJ, Hart AA, Rodenhuis $S$, van 't Veer $L$ : Marker genes for circulating tumour cells predict survival in metastasized breast cancer patients. Br J Cancer 2003, 88: 1091-1094.

12. Harris LN, Solomon N, Roberts L, Ngo T, Abi Raad R, Gioioso C, Kuter I, Smith B, Iglehart JD, Friedman $P$, et al.: Detection and monitoring of circulating tumor cells (CTCs) by CK-19 mRNA in breast cancer patients treated with neoadjuvant chemotherapy: a marker of early recurrence [abstract]. Breast Cancer Res Treat 2005, 94(Suppl 1):1021.

13. Braun S, Vogl FD, Naume B, Janni W, Osborne M, Coombes RC, Schlimok G, Diel I, Gerber B, Gebauer G, et al:: International pooled analysis of prognostic significance of bone marrow micrometastasis in patients with stage I, II, or III breast cancer. N Engl J Med 2005, 353:793-802.

14. Frazier TG, Flynn MS, Sieling BA, Herman M, Rao CS, Gross S, Miller MC, Doyle GV, Terstappen LWMM: Peri-operative assessment of circulating tumor cells in blood, disseminated tumor cells in bone marrow, and tissue gene signatures in patients with primary breast cancer [abstract]. Breast Cancer Res Treat 2005, 94(Suppl 1):1016.

15. Almokadem S, Leitzel K, Harvey HA, Bannon E, Ali SM, Miller MC, Repollet M, Terstappen LWWM, Doyle GV, Frazier T, et al:: Circulating tumor cells in adjuvant breast cancer patients [abstract]. Breast Cancer Res Treat 2005, 94(Suppl 1):2006.

16. Ellis MJ, Miller MC, Cristofanilli M, Budd GT, Stopeck A, Hayes DF, Doyle GV, Matera J, Terstappen LWMM: Prognostic and predictive value of circulating tumor cells in metastatic breast cancer patients treated with endocrine or chemotherapy [abstract]. Breast Cancer Res Treat 2005, 94(Suppl 1):6.

17. Wiedswang G, Borgen E, Schirmer C, Karesen R, Kvalheim G, Nesland JM, Naume B: Comparison of the clinical significance of occult tumor cells in blood and bone marrow in breast cancer. Int J Cancer 2006, 118:2013-2019.

18. Pierga JY, Bonneton C, Vincent-Salomon A, de Cremoux $P$, Nos $\mathrm{C}$, Blin N, Pouillart $\mathrm{P}$, Thiery JP, Magdelenat $\mathrm{H}$ : Clinical significance of immunocytochemical detection of tumor cells using digital microscopy in peripheral blood and bone marrow of breast cancer patients. Clin Cancer Res 2004, 10:1392-1400.

19. Kataoka A, Masuda T, Ohno S, Inoue H, Yamaguchi H, Uchida $Y$, Mimori K, Mori M: Detection of circulating tumor cells in peripheral blood and bone marrow by quantitative RT-PCR assay for cytokeratin-7 mRNA in breast cancer patients [abstract]. Breast Cancer Res Treat 2005, 94(Suppl 1):1020.

20. Benoy IH, Elst H, Philips M, Wuyts H, Van Dam P, Scharpe S, Van Marck E, Vermeulen PB, Dirix LY: Real-time RT-PCR detection of disseminated tumour cells in bone marrow has superior prognostic significance in comparison with circulating tumour cells in patients with breast cancer. Br J Cancer 2006, 94:672-680.

21. Fehm T, Sagalowsky A, Clifford E, Beitsch P, Saboorian H, Euhus D, Meng S, Morrison L, Tucker T, Lane N, et al:: Cytogenetic evidence that circulating epithelial cells in patients with carcinoma are malignant. Clin Cancer Res 2002, 8:2073-2084.

22. Smirnov DA, Zweitzig DR, Foulk BW, Miller MC, Doyle GV, Pienta KJ, Meropol NJ, Weiner LM, Cohen SJ, Moreno JG, et al.: Global gene expression profiling of circulating tumor cells. Cancer Res 2005, 65:4993-4997.

23. Aft RL, Ylagan L, Fleming T, Weilbaecher K, Naughton M, Watson $M$ : Isolation and gene expression profiling of bone marrow disseminated tumor cells from women with locally advanced breast cancer [abstract]. Breast Cancer Res Treat 2005, 94 (Suppl 1):1022.

24. Lynch MD, Cariati M, Purushotham AD: Breast cancer, stem cells and prospects for therapy. Breast Cancer Res 2006, 8:211.

25. Wülfing $P$, Borchard J, Buerger H, Heidl S, Zanker KS, Kiesel L, Brandt B: HER2-positive circulating tumor cells indicate poor clinical outcome in stage I to III breast cancer patients. Clin Cancer Res 2006, 12:1715-1720.

26. Hayes DF, Walker TM, Singh B, Vitetta ES, Uhr JW, Gross S, Rao C, Doyle GV, Terstappen LW: Monitoring expression of HER-2 on circulating epithelial cells in patients with advanced breast cancer. Int J Oncol 2002, 21:1111-1117.
27. Mavroudis D, Apostolaki S, Perraki M, Politaki E, Xenidis N, Stathopoulou A, Lianidou E, Georgoulias V: Detection of HER2 and CK-19 mRNA-positive circulating tumor cells (CTCs) in the peripheral blood of patients with early stage breast cancer [abstract]. Proc Am Assoc Cancer Res 2006, 47:5148.

28. Pachmann K, Camara O, Kavallaris A, Schneider U, Schunemann S, Hoffken K: Quantification of the response of circulating epithelial cells to neodadjuvant treatment for breast cancer: a new tool for therapy monitoring. Breast Cancer Res 2005 , 7:R975-R979. 